\title{
ОСОБЕННОСТИ ЗАКОНОДАТЕЛЬНОГО РЕГУЛИРОВАНИЯ ПРИМЕНЕНИЯ МЕТОДА СТАНДАРД-КОСТИНГ ДЛЯ ЦЕЛЕЙ НАЛОГООБЛОЖЕНИЯ НА ПРИМЕРЕ РАЗЛИЧНЫХ СТРАН
}

\section{FEATURES OF THE LEGISLATIVE REGULATION OF THE APPLICATION OF THE STANDARD-COSTING METHOD FOR TAX PURPOSES ON THE EXAMPLE OF DIFFERENT COUNTRIES}

S. Kokorev

Summary. The subject of the article is the tax regulation of the distribution of differences (deviations)in the value of inventory on the example of the US regulation. At the same time, special attention is paid to the analysis of tax legislation and methodological recommendations of the US Treasury. The relevance of the topic is due to the growing number of enterprises in Europe and America that carry out production (trade) on the territory of Russia, and conduct management accounting using the Standardcosting method. At the same time, in Russia, the possibility of accepting differences (deviations) in the cost of inventory is not available.

The purpose of the study is to identify tax and legal approaches to the interpretation of differences (deviations) and to determine the specifics of their taxation in the United States. The study used methods of comparative analysis and synthesis. For the country under study, the national system of taxation of legal entities, as well as the system of inventory valuation, was analyzed. The tax consequences of typical operations with the distribution of differences (deviations) and their impact on the amount of taxable profit were investigated. As a result of the study of the tax regulation of the distribution of differences (deviations) in the value of inventory on the example of the US regulation, it is concluded that the approach to the tax administration of the distribution of differences (deviations) in the value of inventory by the US Treasury can be adapted in Russia, taking into account the peculiarities of national tax and accounting legislation. The studied methods, when adapted in Russia, will allow, on the one hand, to simplify tax calculations for enterprises using the standard-costing system as a basic one, on the other hand, to simplify tax administration and increase the tax base.

The results of the study can be taken into account by Russian regulatory and legislative bodies to adapt tax legislation to the needs of Western investors. The changes should be aimed not only at generating budget revenues, but also at creating favorable conditions for stimulating investment in the production sector and simplifying tax and accounting administration.

Keywords: standard-costing, distribution of differences (deviations), inventory valuation, tax regulation; US taxation.

\author{
Кокорев Сергей Сергеевич \\ Аспирант, ФГБОУ ВО «Российский экономический \\ университет имени Г.В. Плеханова» \\ srgkkrv@gmail.com
}

Аннотация. Предметом исследования статьи является налоговое регулирование распределения разниц (отклонений) стоимости складских запасов на примере регулирования (ША. При этом особое внимание уделяется анализ налогового законодательства и методических рекомендаций Казначейства США. Актуальность темы обусловлена растущим числом предприятий Европы и Америки, осуществляющих производство (торговлю) на территории России, и ведущих управленческий учет методом (тандард-костинг. В то же время, в России возможность принятия в расходы разниц (отклонений) стоимости складских запасов отсутствует.

Целью исследования является выявление налогово-правовых подходов к интерпретации разниц (отклонений) и определение особенностей их налогообложения в (ША. В исследовании использовались методы сравнительного анализа и синтеза. Для исследуемой страны была проанализирована национальная система налогообложения юридических лиц, а также система оценки складских запасов. Были исследованы налоговые последствия типовых операций с по распределению разниц (отклонений) и их влияние размер налогооблагаемой прибыли. В результате исследования налогового регулирования распределения разниц (отклонений) стоимости складских запасов на примере регулирования США сделан вывод о том, что подход к налоговому администрированию распределения разниц (отклонений) стоимости складских запасов Казначейством США в0зможно адаптировать в России с учетом особенностей национального налогового и бухгалтерского законодательства. Исследованные методики, при их адаптации в России позволят, с одной стороны, упростить налоговые расчеты, для предприятий, использующих систему стандарт-костинг, как базовую, с другой стороны упросить налоговое администрирование и увеличить налоговую базу.

Результаты проведенного исследования могут быть учтены Российскими регулирующими и законодательными органами для адаптации налогового законодательства под потребности западных инвесторов. Изменения должны быть направлен не только на получение бюджетных доходов, но также на создание благоприятных условий для стимулирования инвестиций в сфере производства и упрощения налогового и бухгалтерского администрирования.

Ключевые слова: стандарт-костинг, распределение разниц (отклонений), оценка стоимости складских запасов, налоговое регулирование; налогообложение США. 


\section{Ввемение}

Д анная статья актуальна для предприятий Европы и Америки осуществляющих производство (торговлю) на территории России, ведущих первичный управленческий учет методом Стандард-костинг по принципам МСФО. В соответствии с требованиями местного законодательства, на основании данных первичного учета предприятие обязано формировать бухгалтерскую и налоговую отчетность по стандартам РФ.

Существует способ отдельного учета каждой хозяйственной операции для каждого, используемого учета, но на практике он не применяется из-за высокой стоимости и трудоемкости ведения параллельного учета.

В настоящее время методик ведения Российского налогового учета на основе стандарт-костинга (нормативных цен) не опубликовано, а практический интерес к данной теме возрастает каждый раз при притоке западных инвестиций в отечественное производство или росте импортозамещения.

Представителями бизнеса направляются вопросы в Министерство финансов РФ с целью возможности применения метода стандарт-костинга для целей расчета налога на прибыль. К сожалению, позиция Мин. Фин. РФ состоит в то, что ведение учета готовой продукции по нормативной себестоимости с отнесением отклонений сумм фактических затрат от нормативной себестоимости в налоговом учете текущего периода не предусмотрено Налоговым кодексом РФ, следовательно, для целей налога на прибыль нормативная себестоимость готовой продукции не рассчитывается[4].

По этим причинам изучение вопросов налогообложения западных школ учета представляет в настоящее время наибольший научный интерес.

Для выработки методических рекомендаций предполагается анализ нормативных документов: Налогового кодекса США, Методических рекомендаций казначейства США, разъяснений Казначейства США, обзор Европейской комиссии методологий расчета себестоимости для целей налогообложения. [1], [2], [3], [7].

Из анализа национальных налоговых законодательств США, Англии, Германии, Японии, России [4], [5], [6], [8] следует, что на данный момент метод стандарт-костинга для целей налогообложения прописан в налоговом кодексе США.

При этом одной из важнейших задач, для снижения трудозатрат на ведение учета методом стандарт ко- стинга, по-прежнему является отсутствие комплексной экономико-правовой основы регулирования данного метода учета в налоговом законодательстве. Своевременность внедрения регуляторных механизмов в налоговой сфере как одного из важнейших инструментов государственного регулирования обусловлена высоким интересом западных инвесторов к данному методу учета. В настоящее время налоговые органы различных стран предпринимают попытки применения стандарт-костинга для расчета оценки складских запасов и себестоимости, причем, теоретическое обоснование различных налоговых механизмов, как правило, следует за развитием практики их оборота. Анализ формирующихся на практике подходов к налогообложению и международных правовых систем в различных странах, в условиях отсутствия нормативно-правовой базы в России, представляет бесспорный научно-исследовательский интерес. Это связано не только с необходимостью введения таких методов учета в правовое поле в рамках международной экономики, но и в связи с разработкой режима их налогового регулирования в Российской Федерации.

Особенности налогового регулирования применения метода стандарт-костинг для целей налогового учета различных стран

В США, как стране, массово внедрившей метод учета стандарт-костинг начиная с индустриализации 20-х годов 20 века, метод стандарт-костинг применяется для расчета себестоимости для целей налогового учета. Применение данного метода нормативно закреплено непосредственно в налоговом кодексе. См. секцию 263A («Оценка складских запасов для целей налогового учета» (tax inventory capitalization/ uniform capitalization (UNICAP)) (полная стоимость складских запасов для налогового учета) и и секцию 471 «Общие правила учета складских запасов» (General rule for inventories) (прямые затраты, включенные в стоимость складских запасов для целей налогового учета) [1].

Определение стандарт-костинга для целей налогового учета дано в секции 26 CFR § 1.263A-1 — «Учет затрат на балансе» (Uniform capitalization of costs)

“(F) (3) (ii) Метод стандарт-костинг:

\section{(A) Обшие по^ожения}

Метод стандарт-костинг распределяет соответствующую сумму прямых и косвенных затрат на продукцию, произведенную налогоплательщиком с использованием заранее установленных нормативных цен, без учета затрат, фактически понесенных в течение налогового периода. Налогоплательщик может использо- 


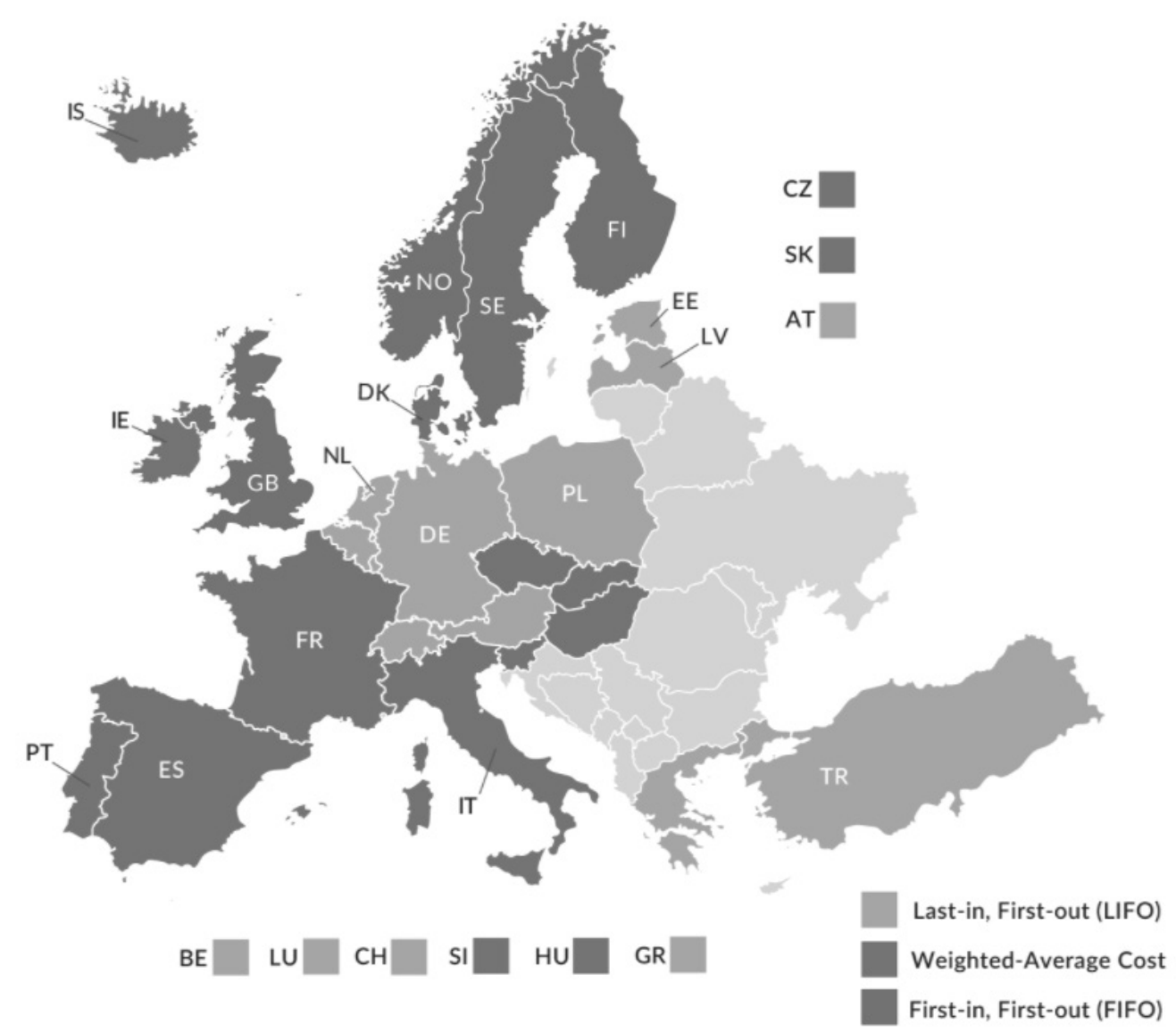

Source: International Tax Competitiveness Index

Рис. 1. По данным сайта International Tax Competitiveness Index:

вать метод стандарт-костинг для учета затрат при условии, что отклонения распределяются в соответствии с процедурами, предписанными в пункте (f) (3) (ii) (B) этой секции. Любая периодическая корректировка нормативных цен, произведенная с целью учета в нормативной цене текущих операционных условий, такие как увеличение производительности или технологии или в ценах, не является изменением методики учета в соответствии с разделом 446 (е). Однако изменение концепции или основы, на которой разрабатываются нормативные цены, представляет собой изменение методики учета, к которому применяется раздел 446 (e).

\section{(В) Опрехеление разниц (отклонений)}

Для целей этой секции чистая положительная разница накладных расходов означает превышение общей суммы нормативных косвенных затрат над общей суммой фактических косвенными затратами, а чистая отрицательная разница накладных расходов означает превышение общей суммы фактических косвенных затрат над общей суммой стандартных косвенных затрат. Правильное использование метода стандарт-костинг требует, чтобы налогоплательщик пропорционально распределял любые чистые отрицательные или чистые положительные отклонения [от нормативных цен] накладных расходов и любые чистые отрицательные или чистые положительные отклонения прямых затрат. Налогоплательщик должен распределить такие отклонения между стоимостью склада и затратами. Однако, если такие отклонения незначительны по сумме относительно общих косвенных затрат налогоплательщика, понесенных в связи с производственной деятельностью и деятельностью по перепродаже за период, то такие отклонения не нужно распределять на балансовую стоимость произведенного или приобретенного для перепродажи имущества, если только такое распределение не производится непосредственно на в финансовой отчетности. Налогоплательщик должен последовательно учитывать как положительные, так и отрицательные отклонения." [1]. 
Стоит отметить, что секция 26 CFR § 1.263A-1 содержит описание прочих методик формирования себестоимости из управленческого учета.

Непосредственное описание методики распределения отклонений для налогового учета указано в методических рекомендациях казначейства США [3]:

1. Выполнить как минимум два расчета распределения разниц (отклонений), если не выполняется одно из нескольких исключений (за исключением Малых и средних предприятий, сельхозпроизводителей, НИИ и т.п.) и/или правило 5\% (если отклонение меньше 5\% от стоимости склада, то вся разница относится на стоимость склада).

- Первый расчет распределения разниц (отклонений) для сырья и товаров (аналог 16 счета в РФ).

- Второй расчет распределения разниц (отклонений) для готовой продукции (аналог 40 счета РФ).

2. Пересчитать себестоимость для целей налогового учета, оставив в ней только расходы, принимаемые для целей налогового учета.

3. Отрицательные разницы (отклонения) запрещено распределять на стоимость склада. Они полностью относятся в себестоимость.

4. Если отклонения для распределения, составляют менее 5\% от стоимости склада, то они включаются полностью в стоимость склада, для целей налогового учета. [3 (10)], [2]. секция 263А (затраты без распределения отклонений), 471 (все затраты, в т.ч., которые не принимаются в бух. учете, например, отклонения).

На территории Европейского союза метод стандарт-костинга для целей налогового учета не применяется [9].

Из 26 охваченных стран 11 разрешают предприятиям использовать LIFO, 10 разрешают только метод средневзвешенной стоимости, а 5 FIFO.

В России налоговый кодекс при определении размера материальных расходов при списании сырья и материалов, используемых при производстве (изготовлении) товаров не допускает использование метода стандарт-костинг [10].

Тем не менее, норму расчета сумм расходов по среднему проценту налоговый кодекс содержит, но относится она к транспортным расходам. Статья 320. Порядок определения расходов по торговым операциям [10].

\section{Выво $\triangle \mathrm{b}$}

Из обзора, налоговых законодательства различных стран, стандарт-костин для целей налогового учета использует только США.

Методические рекомендации казначейства США понуждают налогоплательщика к формированию налоговой базы по сумме выше, чем для целей бухгалтерского учета:

- отрицательные разницы не распределяются, а относятся на себестоимость;

- если отклонение составляет менее 5\% от стоимости склада, то отклонение не распределяется, а относится на стоимость склада.

Применении данных ограничений стандарт-костинг позволяет получить ту же или большую налоговую базу. Бюджет страны здесь получает не меньше налогов.

Налогоплательщик при возможности использования стандарт-костинга в налоговом учете - сокращение издержек от сближения управленческого и налогового учета и некоторое увеличение налоговых платежей.

Несомненно, изменение порядка формирования материальных расходов в налоговом кодексе требует всестороннего изучения, но такой подход будет наиболее юридически обоснованным.

Подходы применения стандарт-костинга в налоговом законодательстве США предоставляют научный интерес для исследования и адаптаци.

\section{ЛИТЕРАТУРА}

1. U.S. Code: Internal Revenue Code: Title 26 Internal revenue code: section 471.— - Режим доступа: https://irc.bloombergtax.com/public/uscode/doc/irc/ section_471 https://www.law.cornell.edu/uscode/text/26/263A, свободный._-Загл. с экрана

2. Department Of The Treasury. Internal Revenue Service. 26 CFR Part 1. [TD9843]. RIN1545-BG07. Allocation of Costs Under the Simplified Methods. AGENCY: Internal Revenue Service (IRS), Treasury. ACTION: Final regulations. Federal Register / Vol. 83, No. 224 / Tuesday, November 20, 2018 / Rules and Regulations. P. 58477 — Режим доступа: https://www.govinfo.gov/content/pkg/FR-2018-11-20/pdf/2018-24545.pdf, свободный. — Загл. с экрана

3. Department Of The Treasury. Internal Revenue Service. Modified Simplified Production Method Federal Register / Vol. 83, No. 224 / Tuesday, November 20, 2018 / Rules and Regulations. P. 58478.— — Режим доступа: https://www.govinfo.gov/content/pkg/FR-2018-11-20/pdf/2018-24545.pdf, свободный.— Загл. с экрана 
4. Е.С. Григоренко Советник государственной гражданской службы РФ 2 класса. Вопрос: можно ли для целей налога на прибыль не рассчитывать фактическую себестоимость готовой и, соответственно, реализованной продукции, а вести весь учет только по нормативной себестоимости, при этом все отклонения суммы фактических затрат от нормативной себестоимости признавать в налоговом учете текущего периода? 19.01.2017// Консультант плюс [Электронный ресурс]. — Режим доступа: www.consultant.ru, свободный.— Загл. с экрана

5. Her Majesty's Revenue and Customs internal manual: BIM33100 — Stock: valuation. — Режим доступа: https://www.gov.uk/hmrc-internal-manuals/ business-income-manual/bim33100, свободный.— Загл. с экрана

6. Dr. Volker Thormählen1. Bull AG, Cologne, Germany. Inventory Valuation according to German Commercial and Tax Legislation // [Электронный ресурс].Режим доступа: https://www.dr-thormaehlen.de/publications/inv_valuation.pdf, свободный.—Загл. с экрана

7. European Commission. A review and Evaluation of Methodologies to calculate tax compliance costs. Luxembourg: Office for Official Publications of the European Communities, 2013 [Электронный ресурс].— Режим доступа: https://ec.europa.eu/taxation_customs/sites/taxation/files/resources/documents/taxation/ gen_info/economic_analysis/tax_papers/taxation_paper_40.pdf, свободный._-Загл. с экрана

8. KPMG Tax Corporation. Taxation in Japan 2017. [Электронный ресурс].— Режим доступа: https://assets.kpmg/content/dam/kpmg/jp/pdf/jp-en-taxationin-japan-201711.pdf, свободный.—Загл. с экрана

9. Elke Asen. TAX Foundation. Inventory Valuation in Europe. March 28, 2019 [Электронный ресурс].— Режим доступа: https://taxfoundation.org/inventoryvaluation-in-europe/, свободный.— -Загл. с экрана

10. «Налоговый кодекс Российской Федерации (часть вторая)» от 05.08.2000 N117-Ф3 (ред. от 29.12.2020) (с изм. и доп.). Статья 254. Материальные расходы, Статья 268. Особенности определения расходов при реализации товаров и (или) имущественных прав.

(с) Кокорев Сергей Сергеевич ( srgkkrv@gmail.com ).

Журнал «Современная наука: актуальные проблемы теории и практики»

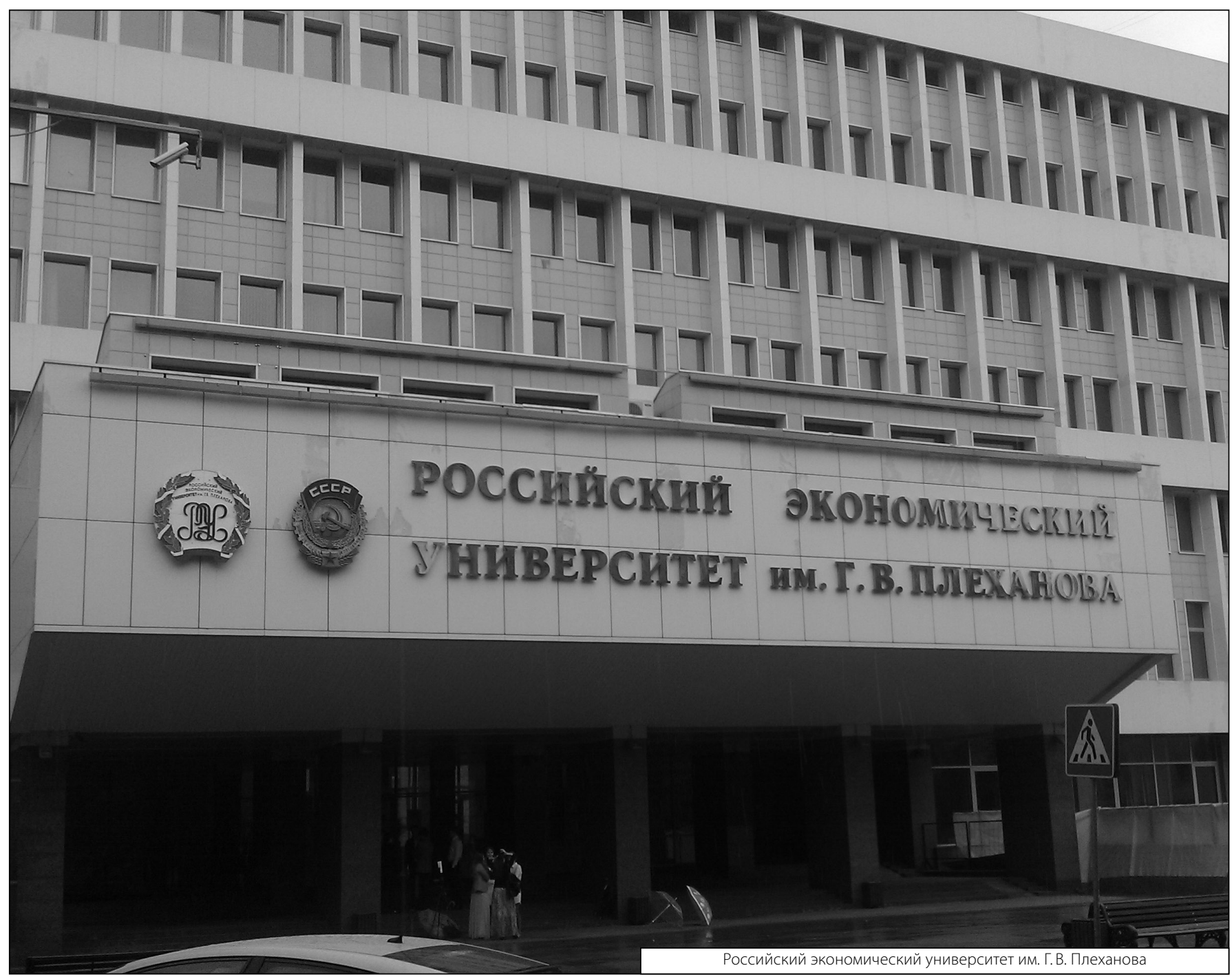

